\title{
A Scenario for a Future European Shipboard Railgun
}

\author{
Stephan Hundertmark \\ French-German Research Institute \\ of Saint-Louis \\ Saint Louis, France \\ Email: stephan.hundertmark@isl.eu
}

\author{
Daniel Lancelle \\ German Aerospace Center \\ Institute of Aerodynamics and Flow Technology \\ Braunschweig, Germany \\ Email: daniel.lancelle@dlr.de
}

\begin{abstract}
Railguns can convert large quantities of electrical energy into kinetic energy of the projectile. This was demonstrated by the $33 \mathrm{MJ}$ muzzle energy shot performed in 2010 in the framework of the Office of Naval Research (ONR) electromagnetic railgun program. Since then, railguns are a prime candidate for future long range artillery systems. In this scenario, a heavy projectile (several kilograms) is accelerated to approx. $2.5 \mathrm{~km} / \mathrm{s}$ muzzle velocity. While the primary interest for such a hypersonic projectile is the bombardment of targets being hundreds of kilometers away, they can also be used to counter airplane attacks or in other direct fire scenarios. In these cases, the large initial velocity significantly reduces the time to impact the target. In this study we investigate a scenario, where a future shipboard railgun installation delivers the same kinetic energy to a target as the explosive round of a contemporary European ship artillery system. At the same time the railgun outperforms the current artillery systems in range. For this scenario a first draft for the parameters of a railgun system were derived. For the flight-path of the projectile, trajectories for different launch angles were simulated and the aero-thermodynamic heating was estimated using engineering-tools developed within the German Aerospace Center (DLR). This enables the assessment of the feasibility of the different strike scenarios, as well as the identification of the limits of the technology. It is envisioned that this baseline design can be used as a helpful starting point for discussions of a possible electrical weaponization of future European warships.
\end{abstract}

\section{INTRODUCTION}

One of the main selling points for a railgun is, that it can convert large quantities of electrical energy into kinetic energy of a projectile. At the same time it was repeatedly demonstrated that muzzle velocities of $2.5 \mathrm{~km} / \mathrm{s}$ can be realized. These two capabilities uniquely qualify railguns as a candidate for a long range artillery system. One of the military platforms, where such a gun could be deployed on, is a larger ship, i.e. a future all-electric frigate or destroyer. In an all-electric ship, the electrical engine needs to be able to accelerate these large ships to velocities of $20 \mathrm{kn}$ to $30 \mathrm{kn}$, thus requiring an electrical power of somewhere between $30 \mathrm{MW}$ to $100 \mathrm{MW}$. As most of the time, the ship will not need all of its installed power for the drive system, it is natural to equipp such a vessel with electrical weapons. The railgun and the high energy laser are prime candidates for such new, electrical weapon systems. When looking at these two systems, the railgun is closely related to the traditional artillery guns being mounted on the current ships. It launches a projectile on a ballistic trajectory, with the only difference to use a magnetic field instead of gun powder as a propellant. As a railgun uses constant acceleration over the barrel length it can achieve higher muzzle velocities than conventional guns of the same length. This higher velocity, in combination with a hypersonic projectile design, translates into a greatly extended range. From the capabilities point of view, a railgun can do all what a conventional gun can do, but better. The navies of the European Union member states have a combined fleet of about 110 frigates and destroyers currently in service [1]. In the future, these will have to be gradually replaced by modern vessels with an electric drive. Even so the total number of ships might shrink due to budget constraints, there is clearly a large market for railgun equipped ships. In this study, it is attempted to develop the key parameters of a railgun system that is needed to match and exceed the capabilities of current shipboard artillery. In addition flight behaviour of a first draft for a hypersonic projectile is evaluated using standard software for preliminary missle design.

\section{Artillery Capabilities of Current Ships}

In France and Germany, there is no clear distinction in name between frigates and destroyers. Instead both types are referred to as frigates. The frigates of both navies are mainly equipped with two calibers for the main gun. Most of the french vessels have a $100 \mathrm{~mm}$ caliber cannon, named "modele 68 " or a variant of it mounted [2]. The german frigates are equipped with the smaller $76 \mathrm{~mm}$ caliber gun from Oto-Melara [3]. Table I lists the most important parametes for these two weapons. The ratio of the projectile to total round mass is about $50 \%$ to $56 \%$. The standard ammunition for these guns uses an explosive warhead. Therefore the amount of carried explosive determines the amount of energy delivered to the target. As an estimate for this energy level one can use the energy content of TNT and scale it by the weight of the bursting-charge. For the $76 \mathrm{~mm}$ gun, the energy released at the target is about $2 \mathrm{MJ}$, while the $100 \mathrm{~mm}$ gun delivers $4 \mathrm{MJ}$. Of course these two numbers are only a superficial criterion, as another important parameter is the accuracy with which a target can be hit. Even so there is not an a-priori reason, as to why railguns could not be used to launch explosive rounds, there is a certain charm in the idea to use the large velocity delivered by railguns to cause the destruction at the target by kinetic energy only. This has the advantage, that it eliminates the need for the costly chain of production, storage, delivery and handling of explosives in addition to reduce the vulnerability of the vessel. For a comparable effect to the existing armament of the current naval vessels, the amount of kinetic energy with which a railgun projectile needs to impact is of the order of $2 \mathrm{MJ}$ to $4 \mathrm{MJ}$. Using an explosive warhead would allow to strongly reduce the impact and therefore the muzzle velocity. The artillery range capabilities of the current european ships are of the order of several tens of kilometers. 


\begin{tabular}{|l|c|c|}
\hline & Modele 68 & Oto-Melara \\
\hline \hline Caliber & $100 \mathrm{~mm}$ & $76 \mathrm{~mm}$ \\
\hline Barrel length & $5.5 \mathrm{~m}$ & $4.72 \mathrm{~m}$ \\
\hline Muzzle velocity & $870 \mathrm{~m} / \mathrm{s}$ & $925 \mathrm{~m} / \mathrm{s}$ \\
\hline Weight of round & $23 \mathrm{~kg}$ & $12 \mathrm{~kg}$ \\
\hline Weight of projectile & $13 \mathrm{~kg}$ & $5-6 \mathrm{~kg}$ \\
\hline Bursting-charge & $1 \mathrm{~kg}$ & $0.4-0.75 \mathrm{~kg}$ \\
\hline Rate of fire & $78 \mathrm{rds} / \mathrm{min}$ & $80 \mathrm{rds} / \mathrm{min}$ \\
\hline Weight of turret & $22 \mathrm{ton}$ & $7.5 \mathrm{ton}$ \\
\hline typical range & $<17 \mathrm{~km}$ & $20-30 \mathrm{~km}$ \\
\hline
\end{tabular}

TABLE I. KEY PARAMETERS OF CURRENT FRENCH AND GERMAN STANDARD NAVAL GUNS (DATA FROM [4], [5]).

\section{DRAFT RAILGUN Dimensions}

To be able to calculate the electrical parameters of a railgun, certain assumptions need to be made. From these assumptions a rough draft for a future railgun system can be derived. This draft, in turn, can be used to refine certain aspects and in an iterative process improve the railgun definition. In this study only the first step is done, resulting in a first sketch of a railgun. Calculations refered to in [6] indicate that a projectile with a muzzle velocity of $2500 \mathrm{~m} / \mathrm{s}$ and a weight above $5 \mathrm{~kg}$ will reach about $200 \mathrm{nmi}$ or more. The velocity at the target will be of the order of $1000 \mathrm{~m} / \mathrm{s}$ to $1500 \mathrm{~m} / \mathrm{s}$. Obviously the range and the final velocity is dependent on the flight path, i.e. the fire angle, and on the aerodynamic properties of the projectile. Nevertheless, without any further studies, the obove assumptions are not unrealistic and will be discussed later in this paper. A $5 \mathrm{~kg}$ projectile with a velocity at the target of $1000 \mathrm{~m} / \mathrm{s}$ to $1500 \mathrm{~m} / \mathrm{s}$ velocity delivers a kinetic energy of $2.5 \mathrm{MJ}$ to $5.6 \mathrm{MJ}$, resulting in approximately the same destructive energy as conventional ammunition delivers explosively. For the acceleration of the $5 \mathrm{~kg}$ projectile in the railgun, an armature and sabot needs to be added. The armature does supply the contact to the rails, while the sabot mechanically attaches the projectile to the armature and acts as a guide through the barrel. As an estimate, an additional mass of $3 \mathrm{~kg}$ is used to accomodate armature and sabot. The total mass of the launch package is $8 \mathrm{~kg}$, resulting in a muzzle energy of $25 \mathrm{MJ}$. The muzzle energy of an electromagnetic launcher can be calculated using:

$$
E=\frac{1}{2} L^{\prime} l I^{2}
$$

relating the inductance gradient $L^{\prime}$, the acceleration length $l$ and the current $I$ to the energy. The inductance gradient $L^{\prime}$ is to a large part determined by the geometry of the rails and the distance in between the rails (the caliber). For practical, simple railguns with a square barrel a good first order approximation is $L^{\prime}=0.5 \mu \mathrm{H} / \mathrm{m}$. Larger values can be obtained by using augmentation methods, adding complexity and weight to the barrel of the launcher. To determine the length of the barrel, a maximal allowed acceleration is assumed. For a constant acceleration the length is given by:

$$
l=\frac{v^{2}}{2 a}
$$

Allowing an acceleration of $50 \mathrm{kgee}$, the minimal length of the barrel is $6.4 \mathrm{~m}$. Using this length and rearranging formular (1)

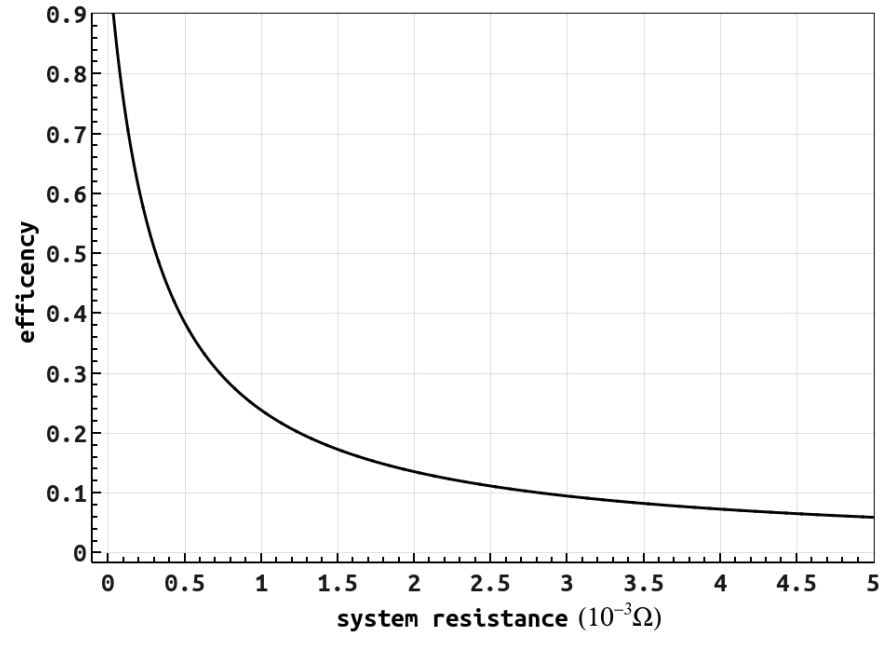

Fig. 1. System efficency as a function of the total system resistance [7].

allows to determine the required current:

$$
I=\sqrt{\frac{2 E}{L^{\prime} l}}
$$

With the values given, the current computes to $I=$ 3.95 MA. This current determines the minimal rail width from an electrical point of view. The maximum linear current density copper can sustain is approximately $I^{\prime}=I /($ width of rails $) \sim 43 \mathrm{kA} / \mathrm{mm}$. This means, that the minimal width is $92 \mathrm{~mm}$. To allow for a safety factor, a caliber of $100 \mathrm{~mm}$ is chosen.

\section{A. Electrical efficency of the launcher}

The amount of energy to be stored in the pulsed power system of the railgun is determined by the muzzle energy multiplied by a factor being inversly proportional to the efficency (ratio of muzzle energy to stored electrical energy) of the launch process. According to [7], the system efficency is dependent on the inductance gradient, on the projectile endvelocity and on the resistance of the system. In this investigation, values for the inductance gradient and the end-velocity were fixed $(0.5 \mu \mathrm{H}$ and $2500 \mathrm{~m} / \mathrm{s})$, leaving the resistance as the only parameter determining the overall system efficency. Contributions to this system resistance are: the power supply, the bus connecting the power supply to the railgun, the rails and the contact resistance of the armature. Figure 1 shows the maximum system efficency that can be reached, given a certain value of resistance. This function drops rapidly with an increasing resistance, reaching approx. $24 \%$ at $1 \mathrm{~m} \Omega$. The lower limit of the system resistance is the contribution from the rails. For $50 \mathrm{~mm}$ thick copper rails, with a caliber of $100 \mathrm{~mm}$, this resistance calculates to $0.4 \mathrm{~m} \Omega$ at full length and half $(0.2 \mathrm{~m} \Omega)$ of this value for the average value during a launch. Using this resistance as a guide, a total system resistance of $0.5 \mathrm{~m} \Omega$ to $1 \mathrm{~m} \Omega$ is a realistic assumption. From figure 1 , this results in an efficency of $24 \%$ to $40 \%$. Using a value of $33 \%$ for the overall efficency, a primary power supply unit being able to store $75 \mathrm{MJ}$ is required for launcher operation. With a charger efficency of $80 \%, 1.6 \mathrm{MW}$ of charging power is needed to allow one round per minute. For a 6 rounds per minute 


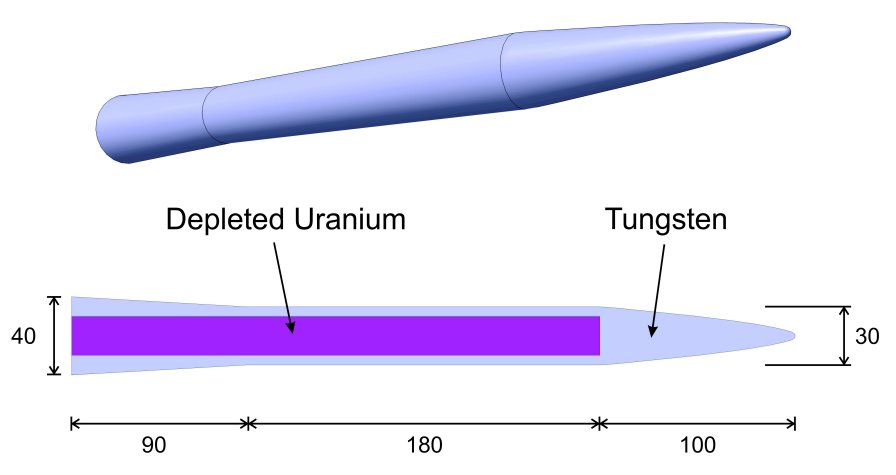

Fig. 2. Hypersonic kinetic energy projectile. All length are given in millimeters.

operation one needs accordingly a charger being capable of delivering 9.6 MW of electrical power.

\section{HyPERSONIC PROJECTILE}

The hypersonic kinetic energy projectile has to fullfill several requirements. To be effective in the target, it shall transfer as much energy as possible to the target. Therefore it needs to have a sufficiently high mass and a high endvelocity. The large velocities experienced by the projectile during its passage through the atmosphere require to pay special attention during the design to low aerodynamic drag and heating. The expected surface temperature needs to be taken into account when choosing the projectile material. Moreover the projectile needs to withstand the high acceleration forces. For this application, the projectiles mass was chosen to be $5 \mathrm{~kg}$. Tungsten was selected as material, because of its high density of $19 \mathrm{~g} / \mathrm{cm}^{3}$ and high melting point of about $3420^{\circ} \mathrm{C}$. This material also increases the armor-piercing capabilities of the projectile. To further increase effectiveness, the pyrophoric property of depleted uranium is used and this material is integrated as core into the projectile. Because of the low melting point of uranium $\left(1130^{\circ} \mathrm{C}\right)$ as compared to tungsten, the whole projectile cannot be manufactured from uranium only. Conversly, as both materials have about the same density, the projectile could be manufactured out of tungsten, only. To reduce aerodynamic drag, a relatively small cross section of the projectile is choosen, with the diameter of the projctile body being $30 \mathrm{~mm}$. The shape of the nose has a power-law form with a rounded nose-tip. This design is the best tradeoff between low aerodynamic drag and low aerodynamic heating. The total length of the projectile is $370 \mathrm{~mm}$. For stable flight, the projectile has a flare with a diameter of $40 \mathrm{~mm}$ at the aft section, instead of fins. Fins are more difficult to design in such a way that they can withstand the expected high temperatures. Such a design would require a more detailed and elaborate design study. A schematical drawing of the used projectile geometry is shown in figure 2 .

\section{TRAJECTORY Simulation}

To calculate the flight path of the projectile, a coupled engineering tool is used. The model is comprised out of a 6-DOF flight mechanics module, an aerodynamics module, and a toolbox to calculate aerodynamic heating. The flight

\begin{tabular}{cccc}
\hline Launch angle & $\mathrm{V}_{\text {hit }}$ & $\mathrm{E}_{\text {hit }}$ & Range \\
\hline \hline $2^{\circ}$ & $1448 \mathrm{~m} / \mathrm{s}$ & $5.2 \mathrm{MJ}$ & $32 \mathrm{~km}$ \\
$10^{\circ}$ & $637 \mathrm{~m} / \mathrm{s}$ & $1 \mathrm{MJ}$ & $100 \mathrm{~km}$ \\
$25^{\circ}$ & $1270 \mathrm{~m} / \mathrm{s}$ & $4 \mathrm{MJ}$ & $303 \mathrm{~km}$ \\
$45^{\circ}$ & $1791 \mathrm{~m} / \mathrm{s}$ & $8 \mathrm{MJ}$ & $496 \mathrm{~km}$ \\
$60^{\circ}$ & $1919 \mathrm{~m} / \mathrm{s}$ & $9.2 \mathrm{MJ}$ & $420 \mathrm{~km}$ \\
$70^{\circ}$ & $1958 \mathrm{~m} / \mathrm{s}$ & $9.6 \mathrm{MJ}$ & $311 \mathrm{~km}$ \\
$80^{\circ}$ & $1975 \mathrm{~m} / \mathrm{s}$ & $9.8 \mathrm{MJ}$ & $132 \mathrm{~km}$
\end{tabular}

TABLE II. RESULTS OF THE SIMULATION FOR DIFFERENT LAUNCH ANGLES. SHOWN ARE THE VELOCITY AND KINETIC ENERGY AT THE TARGET $\mathrm{V}_{h i t}$ AND $\mathrm{E}_{h i t}$ AND THE HORIZONTAL DISTANCE BETWEEN THE LAUNCH AND TARGET POSITION.

mechanics module is an ordinary Runge-Kutta $4^{\text {th }}$ order solver for the equations of translation and rotation. The aerodynamical part of the flight path is calculated using the industry standard tool MISSLE DATCOM [8]. The flight mechanics module provides altitude, velocity, angle of attack and sideslip angle for each time step. MISSILE DATCOM then derives the aerodynamics coefficients. The aerodynamic forces and moments are calculated and provided to the flight mechanics module. Aerodynamic heating is calculated by means of the equation of Fay and Riddell [9], to assess the convective heat flux at the stagnation point. From the net heat balance induced by convective heat flux and surface radiation, the in-stationary temperature distribution within the projectiles material is determined using an implicit scheme for calculating the thermal diffusion in a $1 \mathrm{D}$-slice of the structure. The results for the simulation of the projectiles flight are shown in table II. The launch angle was varied from $2^{\circ}$ up to $80^{\circ}$. The flight trajectories for the different angles are shown in figure 3 . Depending on the projectile launch angle the peak altitude can reach up to $260 \mathrm{~km}$ height and the maximum range is about $500 \mathrm{~km}$ for a launch angle of $45^{\circ}$. From the different simulations, one can observe that a specific range can be reached by two different launch angles, a flat and steep one (as an example, see table II, the cases $25^{\circ}$ and $70^{\circ}$ ). Using the steeper launch angle, a larger part of the trajectory goes through space. Therefore, the distance the projectile has to pass through the atmosphere, is reduced. This leads to an over the course of the flight reduced aerodynamic drag, resulting in a higher impact velocity. For the lower launch angle, the time of travel of the projectile is shorter, but the impact velocity and thus the impact energy are lower as well. The spread is from an impact energy of about $1 \mathrm{MJ}$ for $10^{\circ}$ up to $9.8 \mathrm{MJ}$ for a launching angle of $80^{\circ}$. Figure 4 shows the temperature evolution at the stagnation point for the different launch angles. As the large muzzle velocity results in a large convective heat flux, the surface temperature is increasing rapidly after launch to about $3100 \mathrm{~K}$. Soon, the velocity is decreasing and the altitude is increasing, both reducing the heating of the projectile surface. Once above the atmosphere, the radiative cooling allows for a further reduction in the temperature. Only when the projectile reenters the atmosphere, the stagnation point temperature is increasing again. At one point during the decent, the aerodynamic drag in the increasingly dense atmosphere overcompensates the effect of gravity and the projectile velocity decreases. This results in the turning point in the temperature curves as seen for the launching angels above $25^{\circ}$ at the very end of the flight. 


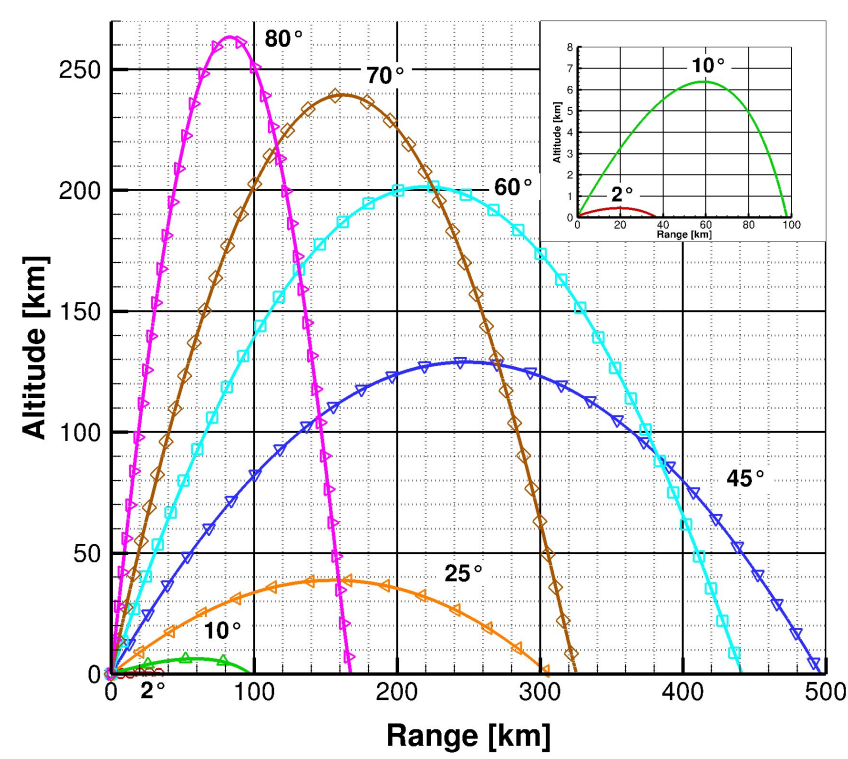

Fig. 3. Flight trajectories for the different launch angles.

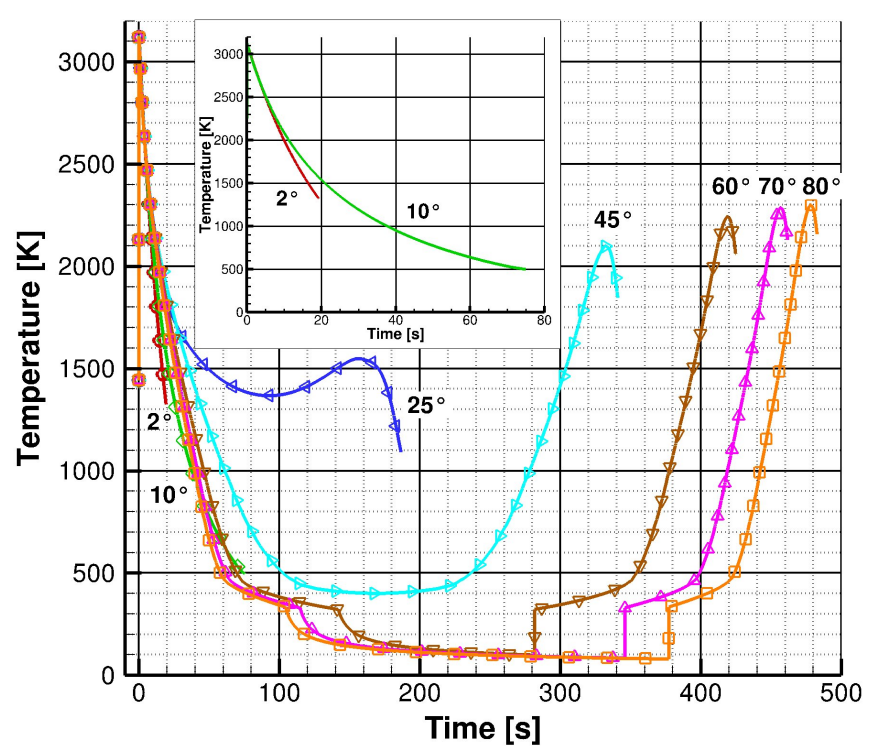

Fig. 4. Surface temperature at the stagnation point for the different launching angles. The steps seen in the curves at around $300 \mathrm{~s}$ are a result of the used atmospheric model, which sets the atmospheric density to zero above a height of $180 \mathrm{~km}$.

\section{SUMMARY}

Starting with a review of current, conventional marine artillery systems, the key parameters of a first draft for a possible railgun implementation were determined. The flight parameters of the projectile were calculated using standard aerodynamic and flight mechanic software. The results of this study are that a $100 \mathrm{~mm}$ square caliber railgun with a barrel length of $6.4 \mathrm{~m}$ is able to accelerate $8 \mathrm{~kg}$ heavy launch packages. Depending on the launching angle, the $5 \mathrm{~kg}$ projectile will have a reach of up to $500 \mathrm{~km}$. For this, the required primary electrical energy is of the order of $75 \mathrm{MJ}$. Such a system would open up new ship

\begin{tabular}{|l|c||l|c|}
\hline Length & $6.4 \mathrm{~m}$ & Prim. energy & $75 \mathrm{MJ}$ \\
\hline Caliber & $100 \mathrm{~mm}$ & Muzzle energy & $25 \mathrm{MJ}$ \\
\hline Projectile mass & $8 \mathrm{~kg}$ & Current & $3.95 \mathrm{MA}$ \\
\hline Muzzle velo. & $2.5 \mathrm{~km} / \mathrm{s}$ & Acceleration & $<50 \mathrm{kgee}$ \\
\hline Range & up to $500 \mathrm{~km}$ & Impact energy & up to $9.8 \mathrm{MJ}$ \\
\hline
\end{tabular}

TABLE III. KEY PARAMETERS FOR THE SHIPBOARD RAILGUN SYSTEM

artillery system capabilities. Further parameters of this gun are summarized in table III. It is the intention of the authors that the results of this study serve as a starting point for further discussions and studies about the capabilities and parameters of a future European shipboard railgun.

\section{ACKNOWLEDGMENT}

Part of this research was financed by the French Ministery of Defence (DGA).

\section{REFERENCES}

[1] http://en.wikipedia.org/wiki/Military_of_the_European_Union\# European_Naval_Forces, (accessed Oct. 2013).

[2] http://en.wikipedia.org/wiki/French_100_mm_naval_gun, (accessed Oct. 2013).

[3] http://en.wikipedia.org/wiki/Otobreda_76_mm, (accessed Oct. 2013).

[4] http://www.navweaps.com/Weapons/WNFR_39-55_m1968.htm, (accessed Dec. 2013).

[5] http://www.navweaps.com/Weapons/WNUS_3-62_mk75.htm, (accessed Dec. 2013).

[6] I. R. McNab, "Parameters for an Electromagnetic Naval Railgun", IEEE Transactions on Magnetics, Vol.37, No. 1, January 2001.

[7] M. Löffler, "Uber die Einkopplung elektromagnetischer Energie in lineare Hochleistungsbeschleuniger" (in german), Ph. D. thesis, Technische Universität Braunschweig, 1988.

[8] S. R. Vukelich, S. L. Stoy and K. A. Burns, "MISSILE DATCON, Volume I Final Report", Flight Dynamic Laboratory, Air Force Wright Aeronautical Laboratories, AFWAL-TR-86-3091, Ohio, 1988.

[9] J. A. Fay and F. R. Riddell, "Theory of Stagnation Point Heat Transfer in Dissociated Air", Journal of Aeronautical Sciences, Vol.25, No. 2, 1958. 